\title{
RESIKO KEGAGALAN INVESTASI PENDIDIKAN : STUDI PADA ANAK PUTUS SEKOLAH MENENGAH PERTAMA (SMP) DI DESA PANGERANAN, BANGKALAN-MADURA
}

\author{
Rais Cahya Tri Putra'; Anita Kristina ${ }^{2}$ \\ Fakultas Ekonomi \& Bisnis, Universitas Trunojoyo Madura \\ Jln. Raya Telang PO BOX 2 Kamal, Bangkalan-Madura \\ E-mail : anita.kristina@trunojoyo.ac.id \\ diterima:22/7/2020; direvisi: 11/8/2020; diterbitkan: 26/9/2021
}

\begin{abstract}
This study analyzes educated failures and future risks for school dropouts in the village of Pangeranan, Bangkalan-Madura. This study uses a qualitative phenomenological approach. The research location is in the village of Pangeranan, Bangkalan-Madura. Data collection was carried out through in-depth interviews with informants, namely parents and children who dropped out of school. Data analysis was carried out through the inductive method with emphasis on the theory or concept of human resource investment and decision making. The findings of this study identify that there are strong factors in dropping out of school decisions, namely internal and external factors. Another finding is that dropping out of school has an impact on job acquisition and low wages. In the future risk of a career, because for them the most important thing is to get a job, no matter the small salary. Then, it can be concluded that the failure of education investment in drop out children includes the risk of future employment. The education department's suggestion is to further follow up on the phenomenon of school dropout students by routine monitoring of each school and to disseminate the importance of education and to provide understanding to the people of Pangeranan Village
\end{abstract}

Keywords: Educational Investment, Decision Risk, Dropout, Investment Failure, Human Capital

\section{PENDAHULUAN}

Persoalan terkait ketimpangan pendidikan banyak yang disebabkan karena pilihan rasional pada investasi pendidikan seseorang (Hallsten, 2017). Keputusan rasional terkait investasi ini dipengaruhi oleh pertimbangan biaya dan manfaat dari beberapa pilihan alternatif ketika memilih untuk melanjutkan pendidikan atau tidak melanjutkan. Investasi pendidikan dilakukan jika ada manfaat yang akan kembali pada dirinya sendiri nantinya dan lingkungan sekitarnya kelak (A. Mukhamad, 2018). Demikian, bisa dipahami bahwa pilihan investasi pendidikan terkait dengan konsekuensi terhadap harapan yang diinginkan nanti. Dan juga menggambarkan sebuah karakteristik kualitas individu terkait pendidikan mereka. Namun, rasional memilih berinvestasi pendidikan (lanjut atau tidak) sangat individual. Masingmasing orang memiliki alasan.

Sementara itu, pilihan untuk tidak melanjutkan pendidikan yaitu karena alasan individu tersebut tidak bertanggung jawab pada masa depan dirinya dan keluarga (Fernandez,Suarez et al., 2016). Permasalahan dengan keluarga (Rabe, 2020), teman sebaya, keterlibatan sekolah, lingkungan, kesehatan, kejahatan di sekolah (McDermott et al., 2019 ; Gao et al., 2019; Thuy Hang et al., 2017). Hal ini mengindikasikan sebagai penyebab untuk putus sekolah. Bahkan bisa jadi kegagalan kemampuan dalam memahami lingkungan mereka (anak putus sekolah) awalnya ditunjukkan dengan perilaku membolos, sering mendapatkan bimbingan akademis dari pihak sekolah. (Masalah yang terkait kelembagaan juga menjadi sumber penyebab, yakni, kebijakan/aturan dari sekolah. Hubungan 


\section{Jurnal Ilmiah Ekonomi dan Bisnis}

Vol. 18. No.1,Maret $2021: 37-46$

EISSN : $2442-9813$

ISSN : $1829-9822$

antara guru dan siswa bisa menjadi gagal, jika terdapat perbedaan cara pandang terkait manajemen kelas dalam pembelajaran. Begitu juga budaya pada masyarakat tertentu juga dapat menyebabkan faktor pilihan putus sekolah (E. Barberis \& Ripamonti, 2018) dan persoalan kemiskinan atau ekonomi menjadi penyebab juga (Islam Sarker et al., 2019 ; Mayra \& Mauricio, 2018).

Pilihan putus sekolah banyak dialami oleh anak-anak perempuan yang berasal dari keluarga miskin (Psacharopoulos \& Patrinos, 2018 ; Mohan et al., 2018). Faktor lainnya disebabkan jumlah saudara kandung mereka banyak (T. Lestari \& A. Setyadharma, 2019), anak-anak yang berada pada komunitas masyarakat pedesaan yang orang tuanya miskin dan tidak memiliki orientasi pada pendidikan anak-anaknya (Ansary, 2017), mereka juga dibebankan pada biaya sekolah (Kim, Donggeun \& Kim, Seoyong, 2018), dan latar belakang budaya keluarga "kelas sosial" sebuah keluarga akan menjadi pembentuk cara pikir dan karakteristik psikologi seseorang yang malas, tidak memiliki semangat sekolah (Ghignoni, 2017). Demikian, dapat dipahami bahwa keputusan tidak lanjut sekolah ini akan membawa pada risiko tertentu.

Risiko kegagalan pendidikan pada anak putus sekolah akan ditunjukkan dengan anak memiliki IQ rendah, kesulitan nalar (Gubbels et al., 2019), resiko pada saat besarnya akan nanti berdampak jika mereka dewasa. Mereka akan miskin pengalaman belajar dan berketerampilan (Francois et al., 2020). Lalu, ketika berhadapan dengan pekerjaannya nanti, mereka berpeluang mendapatkan pekerjaan yang marginal (terpinggirkan). Hal ini dikarenakan peluang berkesempatan mendapatkan pekerjaan dengan upah tinggi relatif rendah (Hedges, 2019). Sedangkan terdapat pula pengorbanan anak-anak perempuan akan meluangkan waktunya untuk mengurusi keluarga, beban pekerjaan rumah tangga akan menjadi pekerjaan sehari-hari. Pekerjaan ini hanya bersifat sosial. Sementara ada efek sederhana yaitu mereka tidak bisa melanjutkan ke pendidikan tinggi (Caucutt \& Lochner, 2020). Beberapa risiko tersebut menunjukkan bahwa tidak ada nilai investasi yang dapat dimanfaatkan.

Penelitian ini akan mencoba untuk menganalisis kegagalan berpendidikan dan risiko di masa depan bagi anak putus Sekolah Menengah Pertama (SMP) yang tidak melanjutkan kejenjang selanjutnya yakni Sekolah Menengah Atas (SMA), berada di desa Pangeranan, Madura. Namun, sebenarnya desa Pangeranan merupakan wilayah desa yang berjarak sangat dekat dengan kota Bangkalan, sehingga akan banyak dijumpai sarana ataupun prasana pendidikan sudah memadahi, sudah banyak pendidikan formal disekitar serta jarak antar desa ke pendidikan formal sangat dekat. Hal ini diindikasikan bahwa Masyarakat Madura mempunyai kebiasaan melakukan pernikahan atau perjodohan antar anggota keluarga. Tradisi perjodohan di daerah desa Pangeranan Bangkalan-Madura masih sangat membudaya disebut mapolong tolang (mengumpulkan tulang yang bercerai-berai). Hal tersebut banyak ditemui anak putus sekolah di desa Pangeranan ini.

Penelitian ini akan mencoba melakukan eksplorasi temuan atas pilihan-pilihan keputusan untuk tidak melanjutkan sekolah, mengapa hal tersebut terjadi? Dan bagaimana diskusi atas pilihan keputusan putus sekolah pada risiko yang mereka hadapi di masa depan?. Dengan demikian, penelitian ini akan berkontribusi secara teoritis yaitu pengembangan konsep keputusan investasi pendidikan dan risikonya. Dan juga kontribusi secara empiris praktis, penelitian ini akan membantu memahami 
pada masyarakat dan menekankan pentingnya memikirkan dan mempertahankan pendidikan, karena ada risiko yang akan mereka dapat jika mereka dewasa.

\section{TINJAUAN PUSTAKA}

Bentuk investasi sumber daya manusia salah satunya berupa pendidikan. Pendidikan merupakan suatu usaha sadar dan terencana untuk mewujudkan suasana belajar dan proses pembelajaran agar peserta didik secara aktif mengembangkan potensi dirinya untuk memiliki kekuatan spiritual keagamaan, pengendalian diri, kepribadian, kecerdasan, akhlak mulia, serta keterampilan yang diperlukan dirinya, masyarakat, bangsa dan negara (UU No. 20 Tahun 2003 tentang sistem Pendidikan Nasional). Sementara itu, tidak semua orang dapat menempuh pendidikan dengan berkelanjutan sesuai jenjang yang seharusnya mereka tempuh, karena sebagian dari mereka yang putus sekolah. Putus sekolah merupakan predikat yang diberikan kepada mantan peserta didik yang tidak mampu menyelesaikan suatu jenjang pendidikan tersebut, sehingga tidak dapat melanjutkan studinya ke jenjang pendidikan berikutnya (Gunawan, 2011).

Kegagalan investasi pendidikan akan menimbulkan risiko-risiko di masa yang akan datang. Penelitian Syahdan (2017) dan Fobia (2020) yang menunjukkan bahwa terdapat hubungan positif yang signifikan antara keterampilan kerja dengan produktivitas kerja. Pekerja dengan tingkat sekolah yang berbeda dapat memiliki penghasilan yang berbeda pula. Kondisi sosial ekonomi mencakup pekerjaan, pendidikan dan pendapatan masyarakat. Kegagalan investasi juga dikarenakan tingkat pendidikan orang tua yang rendah dimana pada orang tua juga memiliki tingkat pendidikan yang rendah hal ini dimana hal tersebut dapat dijadikan contoh atau acuan negatif bagi pola pikir anak putus sekolah. Tinggi rendahnya pendidikan orang tua, besar kecilnya penghasilan dan lain-lain, semua itu turut mempengaruhi pencapaian belajar anak. Kondisi ekonomi yang rendah merupakan faktor yang berasal dari luar diri anak berasal dari orang tua yakni keadaan ekonomi keluarga, perhatian orang tua, hubungan orang tua yang kurang harmonis, latar belakang pendidikan orang tua, ataupun lingkungan yang kurang mendukung seperti jarak rumah dengan sekolah yang jauh. Untuk meningkatkan kualitas tenaga kerja dengan cara pelatihan psikologi, pelatihan motivasi serta pelatihan kerja berbagai kejuruan, penerapan disiplin kerja, dan manajemen sosial (Adianto, 2018). Peran orang tua juga dapat membantu menemukan dan menumbuhkan bakat anak serta menciptakan lingkungan dan memberikan stimulasi, yaitu mendampingi, mengekspos, menemani, menyemangati, menjadi teman diskusi, dan menguatkan anak (Trisnawati et al., 2020).

\section{METODE PENELITIAN}

Fokus penelitian ini dilakukan pada persoalan kegagalan berpendidikan dan risiko di masa depan bagi anak putus sekolah. Penelitian ini dilakukan dengan tahapan observasi dan pengumpulan data dilakukan dengan wawancara secara mendalam dengan informan, yakni orang tua dan anak putus sekolah yang tidak lanjut ke Sekolah Menengah Atas (SMA) yang ada di desa Pangeranan, BangkalanMadura dengan menitikberatkan pada teori atau konsep investasi sumber daya manusia dan pengambilan keputusan. Kemudian data diolah dan dianalisis secara induktif dengan pendekatan kualitatif fenomenologi. Uji keabsahan data dilakukan melalui uji kredibilitas yakni melakukan uji dengan teknik memaknai dan diskusi dengan teori atau konsep investasi sumber daya manusia. 
Jurnal Ilmiah Ekonomi dan Bisnis

Vol. 18. No.1,Maret 2021 : 37-46

EISSN : $2442-9813$

Dan uji validitas dengan teknik triangulasi sumber.

\section{HASIL DAN PEMBAHASAN}

Keputusan pada anak putus sekolah terjadi karena faktor internal anak itu sendiri. Faktor internal adalah faktor yang berasal dari dalam diri seperti kurangnya minat anak, anak ingin bebas dan anak memang tidak suka sekolah dalam artian anak memang ingin berhenti sekolah (Lestari Budi, 2020). Hal ini sama dengan apa yang disampaikan informan, sebagai berikut :

"Ye jiyah mas, le lok niat, males se ajerrah mas, apapole pesse adek mas, yella lok lanjut asekolah ke SMA pole mas" (Ya itu, sudah tidak niat, malas untuk berlajar dan apalagi uang tidak ada, Ya, sudah saya tidak lanjut ke SMA lagi)

Informan memutuskan untuk putus sekolah, dilatarbelakangi oleh tidak adanya kemauan sekolah serta kondisi ekonomi yang rendah. Anak putus sekolah menemui keadaan dimana mengalami keterlantaran karena sikap dan perlakuan orang tua yang tidak memberikan perhatian yang layak terhadap proses tumbuh kembang anak tanpa memperhatikan hak-hak anak untuk mendapatkan pendidikan yang layak (Darmawan, 2019). Hal ini juga sejalan dengan Hermina \& Didik (2019) bahwa pemenuhan hak pendidikan tersebut diperoleh secara formal di sekolah, secara informal melalui keluarga. Sedangkan pada temuan terdapat kemauan anak itu sendiri yang tidak mau bersekolah dikarenakan malas, malu. Ada juga anak tidak bersekolah yaitu untuk membantu orang tuanya bekerja untuk memenuhi kebutuhan ekonomi keluarga.

Kemudian, temuan berikutnya yaitu adanya kemampuan berpikir rendah, pengetahuan dan pemahaman tingkat rendah, dimana kurang kesadaran akan pentingnya bersekolah. Berikut pernyataan yang disampaikan informan :

"Terro nyareh pesse bhein mas, norok kakak/bapak nyering dek tasek, sekalian ghebey ba namba mas abantu reng tuah" (Ingin mencari uang saja, ikut kakak/ayah mencari ikan di laut, sekalian untuk menambah penghasilan membantu orang tua).

Faktor kemampuan berpikir rendah menjadi alasan informan dalam memutuskan untuk putus sekolah. Dengan kondisi ekonomi rendah, informan berkeinginan ingin untuk mendapatkan penghasilan tambahan untuk keluarga tanpa memikirkan resiko dimasa depan tanpa pendidikan yang cukup. Hal ini selaras dengan penelitian Lestari Budi (2020) yaitu hasil menunjukkan faktor yang menjadi penyebabnya seperti keinginan untuk bekerja, membantu otang tua, dan akses menuju ke sekolah yang jauh. Padahal pola pikir berpengaruh terhadap peningkatan kemungkinan anak putus sekolah serta rendahnya kesadaran akan pentingnya pendidikan sebagai investasi masa depan yang menyebabkan anak putus sekolah (T. Lestari \& A. Setyadharma, 2019).

Temuan lain ditunjukkan bahwa kondisi ekonomi keluarga atau rendahnya pendapatan orang tua si anak sehingga perhatian orang tua lebih banyak tercurah pada upaya untuk memenuhi kebutuhan keluarga. Berikut pernyataan yang disampaikan informan :

"Pas-pasan, apah se ekebutoh, se egebey ngakan jeh pas, ye dek remmah pole cong, alakonnah ken nyering mon osom, mon lok osom ye kabbi se ekelakoh, alakoh se ollennah cong." (Berkecukupan, cukup didigunakan makan, mau bagaimana lagi, kerjanya hanya mencari ikan di laut itupun jika musim, jika tidak musim semuanya yang dilakukan asal dapat upah.)"

Faktor kondisi ekonomi keluarga menjadi faktor utama anak putus sekolah. Dimana kondisi ekonomi yang rendah 
karena pendapatan keluarga tidak menentu dan tidak dapat memenuhi kebutuhan pada pendidikan. Akibat ketidakmampuan ekonomi keluarga dalam membiayai sekolah dan tidak adanya perhatian orang tua terhadap anaknya, menimbulkan masalah pendidikan seperti masalah anak putus sekolah. Keputusan orang tua untuk mengeluarkan anak mereka dari pendidikan tidak tergantung pada gender tetapi tergantung pada status ekonomi mereka (Ansary, 2017)

Pada penelitian juga ditemukan bahwa orang tua memiliki andil penting dalam pendidikan anak, dimana tingkat pendidikan anak salah satunya dipengaruhi oleh pemikiran orang tua. Jika orang tua tidak memiliki pemikiran yang terbuka, tidak mau menerima perkembangan yang ada, maka kesadaran akan pendidikan terhadap anak-anak mereka juga kurang. Berikut pernyataan yang disampaikan informan :

"Terronnah ye epelanjut bhein cong, polannah pendidikan jeh penting, makle lok padeh so bapak bik engko cong, ken tadek biayannah" (Ingin dilanjutkan saja, bagaimanapun juga pendidikan itu penting, dan lagi agar tidak sama dengan Bapak sama saya, hanya saja, biaya tidak ada).

Rasa pesimis orang tua karena tidak mampu menyekolahkan anak karena biaya pendidikan mahal selalu muncul, sehingga berakibat anak mengalami putus sekolah dengan pendidikan formal yang rendah. Orang tua yang memiliki keinginan untuk menyekolahkan anaknya akan selalu mendukung terutama dalam hal pendidikan, sebab hal ini juga akan sangat berpengaruh dalam penentuan masa depan anak. Hal ini selaras dengan penelitian Trisnawati et al., (2020) bahwa peran orang tua membantu menemukan dan menumbuhkan bakat anak serta menciptakan lingkungan dan memberikan stimulasi, yaitu mendampingi, mengekspos, menemani, menyemangati, menjadi teman diskusi, dan menguatkan anak. Jadi motivasi orang tua berpengaruh signifikan terhadap pendidikan anak (Idrus, 2019). Dengan demikian, sebenarnya anak membutuhkan motivasi, yaitu mendorong dan mempertahankan aktivitas tertentu agar tercapainya sebuah tujuan (Dale $\mathrm{H}$. Schunk, 2016), seperti seharusnya memberikan motivasi untuk tetap sekolah yaitu sebagai bentuk upaya mencapai tujuannya nanti.

Temuan lainnya bahwa kesamaan situasi pengalaman keluarga/masyarakat yang juga mempunyai kondisi yang sama secara ekonomi, dan pemahaman yang kurang pada pentingnya sekolah. Sebenarnya dengan memiliki pendidikan yang cukup maka seseorang akan mengetahui mana yang baik dan mana yang dapat menjadikan seseorang menjadi berguna baik untuk dirinya sendiri maupun untuk orang lain yang membutuhkannya. Berikut pernyataan yang disampaikan informan :

"Ye le padeh cong, bapa'eh bhein lulusan SMP, engko ye SD, neng kannak adek se lulusan SMA cong, mangkannah tang anak se eyarep makle lulus sampe SMA" (Ya sama saja, Bapaknya saja lulusan SMP, saya SD. Disini gak ada yang lulusan SMA, maka dari itu saya berharap anak saya lulus sampai SMA).

Dari jawaban informan, terjadi kesamaan situasi terhadap tingkat pendidikan orang tua dan anak, dimana pada orang tua juga memiliki tingkat pendidikan yang rendah hal ini dimana hal tersebut dapat dijadikan contoh atau acuan negatif bagi pola pikir anak putus sekolah. Tinggi rendahnya pendidikan orang tua, besar kecilnya penghasilan, cukup atau kurang perhatian dan bimbingan orang tua, rukun atau tidaknya kedua orang tua, akrab atau tidaknya hubungan orang tua dengan anak - anak, tenang atau tidaknya situasi dalam rumah, semuanya mempengaruhi keberhasilan 
Jurnal Ilmiah Ekonomi dan Bisnis

Vol. 18. No.1,Maret 2021 : 37-46

EISSN : $2442-9813$

ISSN : $1829-9822$

belajar. Hasil penelitian E. Barberis \& Ripamonti (2018) menunjukkan bahwa tinggal di lingkungan dengan kehidupan budaya yang hidup dapat meningkatkan keterampilan non-kognitif siswa, sehingga mendorong keterlibatan mereka dalam kegiatan formatif dan pengembangan modal manusia mereka. Begitu juga dikarenakan pendidikan orang tua yang rendah tidak dapat membimbing anaknya dalam memberi masukan yang lebih baik dalam bertindak khususnya bidang pendidikan (Lestari Budi, 2020). Serta pada temuan lain yaitu karakteristik orang Madura itu sendiri, menurut Effendy H (2020), faktor anak putus sekolah ini dibentuk oleh kebiasaan budaya/karakteristik masyarakat Madura. Dimana hal tersebut menjadi salah satu faktor anak putus sekolah di desa Pangeranan. Berikut pernyataan yang disampaikan informan :

"Lambek yee engko ejuduin kiah bik tang reng tuah cong, engko ye norot bhein dek ocakna tang reng tuah, mareh lok bennyak tanggungan kiah, apapole tang reng tuah le kenal dek keluarga tang lakeh, reng madura lakar dekiyeh cong, sampe setiah yee bedeh ken tak bennyak ngan lambek" (Waktu dulu orang tua saya menjodohkan saya, saya nurut saja kepada orang tua, supaya tidak banyak tanggungan juga, apalagi keluarga suami saya kenalan orang tua saya, sampai sekarang masih ada mengenai perjodohan hanya saya tidak banyak seperti dulu".

Berdasarkan jawaban informan diatas, dapat disimpulkan tradisi perjodohan yang terjadi di desa Pangeranan saat ini masih sangat membudaya. Bahkan masyarakat setempat menganggap hal tersebut sudah terbiasa terjadi karena menurut mereka itu baik bagi anak-anak mereka. Selain itu perjodohan dini juga masih terjadi walaupun sudah tidak banyak, karena masyarakat menganggap dengan melakukan perjodohan dini bisa mengurangi tanggungan keluarga.

Risiko di masa depan yang didapat dari kegagalan investasi manusia salah satunya perolehan perkerjaan yang rendah, yang dikarenakan kurangnya wawasan atau pengalaman dari tenaga kerja. Seperti apa yang dinyatakan informan :

"Mon pekerjaan gitak olle mas, mlarat mas nyareh kelakoan, mon bedeh se ekelakoh yee ekelakoh mas se penting olle pesse mas tekkak diddik" (Kalau pekerjaan belum dapat, kalau ada kerjaan ya saya kerjakan, yang penting dapat uang walaupun sedikit).

Dari penjelasan informal bahwasanya tidak ada kesempatan kerja yang tersedia yang diakibatkan kualitas tenaga kerja itu sendiri sehingga tenaga kerja hanya memikirkan seadanya untuk pendapat penghasilan seadanya. Dengan demikian upaya-upaya tersebut dapat menghasilkan upah (Febrianti, 2019), sehingga faktor yang dapat mendorong meningkatnya produktivitas tenaga kerja diantaranya motivasi kerja dan pengalaman kerja dan pendidikan. Seorang yang memiliki pendidikan tinggi akan cenderung dalam mendapatkan pekerjaan yang layak (Soebagiyo and Hasmarini, 2017).

Temuan lainnya yang menjadi risiko adalah mereka bekerja pada area informal. Pekerjaan ini mereka pilih juga karena untuk mendapatkan upah yang didapat, dan informan bekerja untuk diri sendiri dan dikonsumsi untuk diri sendiri. Hal ini disebabkan karena tingkat pendidikan yang rendah informan. Berikut pernyataan informan :

"Ye biasah mas, norok kakak/Bapak ke tasek, ye mon lok osom yee biasannah ngebey lajengan pas ajuwel mas, apapole ken lulusan SMP mas, lakonnah ye kadik jiyah le lok kerah neng kantoran" (Ikut kakak/Bapak ke laut, kalau tidak musim biasanya membuat layangan dan dijual, apalagi saya hanya 
lulusan SMP mas, ya seperti kerjanya tidak bakal bisa bekerja di kantor).

Dari penjelasan informan bahwasanya perkerjaan yang didapat hanya seorang nelayan yang merupakan sektor informal, hal itu disebutkan oleh informan dikarenakan tingkat pendidikan yang rendah yakni tingkat lulusan SMP dan informan hanya memikirkan asal mendapatkan penghasilan tanpa melihat besar kecil nominal yang diberikan. Pekerja pada sektor informal dikendalikan oleh profil tingkat pendidikan berpendidikan tidak tamat SD sampai SD Sederajat bekerja di sektor informal (Yuniati, 2019). Sementara itu menurut penelitian Adianto (2018) bahwa untuk peningkatan kualitas tenaga kerja wajib dilakukan, salah satunya melalui pendidikan, pelatihan kerja berbagai kejuruan, penerapan disiplin kerja, dan manajemen sosial.

Pada akhirnya pekerjaan yang terima berdampak pada perolehan upah. Tingginya pendapatan akan mampu meningkatkan konsumsi masyarakat dan tidak tergolong miskin. Ungkapan informan, sebagai berikut:

"Adek upah mas, soallah ken alakoh nyering jukok, ajiyah bhein tergantung ollennah bennyak apah enjek, intinnah lok nentoh mas ollennah berempah, paling mon upah yee pas eyolok oreng soro alakoh serabutan mas ajiyah bhein biasannah ken eberrik 50100 tergantung lakonnah apah" (Tidak ada upah, Dapat uang dari nangkap ikan, itu saja tergantung banyak dikitnya ikan yang didapat, intinya tidak pasti dapatnya berapa. Paling kalau dapet bayaran kalau dipanggil orang untuk kerja serabutan, itupun dapatnya tidak banyak hanya sekitar Rp. 50.000Rp.100.000).

Kondisi informan sebagai pekerja dengan upah rendah hal ini disebabkan karena resiko dari rendahnya tingkat pendidikan informan. Hasil penelitian
Akbariandhini (2020) menunjukkan bahwa variabel tingkat pendidikan berpengaruh signifikan terhadap pendapatan, serta menunjukkan variabel berpengaruh positif lainnya yaitu jenis kelamin dan status perkawinan, sedangkan pengalaman kerja berpengaruh signifikan terhadap upah.

Risiko lain adalah keterampilan yang rendah akan sulit mendapatkan pekerjaan dan tidak dapat penghasilan cukup. Berikut pernyataan yang disampaikan informan :

"Mon keterampilan adek mas, lok taoh pa apah, ken le taoh nganoh jering bik ngebey lajengan mas," (kalau keterampilan gak ada, Tidak tahu apa-apa, hanya memiliki keterampilan membuat/memperbaiki jaring dan membuat layangan).

Jawaban informan tersebut dapat dimaknai bahwa keterampilan yang didapat dari lingkungan keluarga dengan harapan bisa membantu keluarga. Sehingga keterampilan kerja merupakan hal yang bersifat individual setiap individu akan memiliki tingkat keterampilan yang berbeda tergantung pada kemampuan dan pengalamannya. Kurangnya keahlian serta ketrampilan tenaga kerja tersebut antara lain disebabkan oleh tingkat pendidikan yang rendah. Artinya, bahwa terdapat hubungan positif yang signifikan antara keterampilan kerja dengan produktivitas kerja (Syahdan, 2017; Fobia, 2020).

\section{KESIMPULAN DAN SARAN}

Berdasarkan hasil pada penelitian ini, maka dapat disimpulkan : (1) Faktor kuat keputusan putus sekolah adalah anak tidak memiliki kemauan sekolah, kemampuan berpikir rendah, kondisi ekonomi keluarga, dan keinginan orang tua, serta terdapat kesamaan situasi yang sama dengan pengalaman keluarga, tetangga dan masyarakat sekitar. (2) Putus sekolah berdampak pada perolehan pekerjaan yang rendah, anak putus sekolah bekerja pada 


\section{Jurnal Ilmiah Ekonomi dan Bísnis \\ Vol. 18. No.1,Maret 2021 : 37-46}

EISSN : $2442-9813$

ISSN : 1829-9822

area informal, upah rendah dan mereka memiliki ketrampilan yang rendah. Risiko di masa depan akan karir, mereka mengabaikan hal ini, karena bagi mereka yang terpenting adalah mendapatkan pekerjaan, tidak peduli upah kecil dan tidak ada perubahan karir pekerjaan. Dengan demikian, kegagalan investasi pendidikan anak putus sekolah memuat risiko pekerjaan yang di dapatkan pada masa depan.

Adapun saran yang dapat diberikan adalah: Saran bagi Dinas Pendidikan Kabupaten Bangkalan agar melakukan pemantauan rutin kepada setiap sekolah yang terdeteksi siswa yang keluar dari sekolah atau tidak melanjutkan sekolah dan diharapkan juga hasil penelitian ini menjadi bahan pada pengembangan penelitian berikutnya yang berkenaan dengan isu biaya resiko yakni menghitung biaya kerugian investasi pendidikan sebagai kegagalan investasi pendidikan di masa depan.

\section{DAFTAR PUSTAKA}

A. Mukhamad, S. . M. A. (2018). Determinant Return To Education In Indonesia. Jurnal Manajemen Dan Sistem Informasi, 3(4), 52-69, https://doi.org/https://doi.org/10. 17509/manajerial.v17i1.9761\%0 A, ISSN: 1412-6613, E-ISSN: 2527-4570

Adianto, J. (2018). Peningkatan Kualitas Tenaga Kerja Dalam Menghadapi ASEAN Economy Community. Jurnal Pekerjaan Sosial, 1(2), 77-

86.https://doi.org/https://doi.org/ 10.24198/focus.v1i2.18261

Akbariandhini, M. (2020). Analisis Faktor Tingkat Pendidikan, Jenis Kelamin, dan Status Perkawinan Terhadap Pendapatan Di Indonesia Berdasarkan IFLS-5. Jurna. $l$ Pendidikan Ekonomi Manajemen dan Keuangan, 4(1),
13-22,

http://dx.doi.org/10.26740/jpeka.v 4n1.p13-22, ISSN: 2579-5716

Ansary, M. R. (2017). Socio-economic Factors of Dropout Situation in Rural Primary Education: A Study of Two Villages in Rajshahi District. Sociology and Criminology, 5 (2), 3-6. https://doi.org/10.4172/23754435.1000176, ISSN: 2375-4435

Caucutt, E. M., \& Lochner, L. (2020). Early and Late Human Capital Investments, Borrowing Constraints, and the Family. Journal of Political Economy. 128 (3), 1065-1147. https://doi.org/10.1086/704759

Dale H. Schunk, M. K. D. (2016). Handbook of Motivation at School: Self-Efficacy Theory in Education. In Self-Efficacy Theory in Education.Routledgehanbooks. Inggris.

E. Barberis, \& Ripamonti. (2018). The Effect of Cultural Capital on High School Dropout: An Investigation in the Italian Provinces. Soc Indic Res. 13(9), 1257-1279. https://doi.org/https://doi.org/10.10 07/s11205-017-1754-6

Febrianti, R. N. (2019). Pengaruh Motivasi Kerja dan Pengalaman Kerja Terhadap Produktivitas Tenaga Kerja Pengrajin Kuningan Di Kecamatan Tapen Kabupaten Bondowoso. Jurnal Ilmiah Ilmu Pendidikan, Ilmu Ekonomi, Dan Ilmu Sosial, 13(1), 42-49, https://doi.org/https://doi.org/10.19 184/jpe.v13i1.10419 ISSN 25487175.

Fernandez-Suarez, A., Herrero, J., Perez, B., Juarros-Basterretxea, J., \& Rodriguez-Diaz, F. J. (2016). Risk Factors for School Dropout in a Sample of Juvenile Offenders. Frontiers in Psychology. 7, 1-7, 
https://doi.org/10.3389/fpsyg.201 6.01993

Francois, A., Panel, S., \& Weill, L. (2020). Educated Dictators Attract More Foreign Direct Investment. Journal of Comparative Economics. 48(1), 37-55.

https://doi.org/10.1016/j.jce.2019 .11 .006

Gao, S., Yang, M., Wang, X., Min, W., \& Rozelle, S. (2019). Peer Relations and Dropout Behavior: Evidence From Junior High School Students in Northwest Rural China. International Journal of Educational Development, 73(1), 1-19, https://doi.org/10.1016/j.ijedudev .2018 .04 .001

Ghignoni, E. (2017). Family Background and University Dropouts During The Crisis: The Case of Italy. Higher Education. 73 (1), 127151.

https://doi.org/10.1007/s10734016- 0004-1

Gubbels, J., van der Put, C. E., \& Assink, M. (2019). Risk Factors for School Absenteeism and Dropout: A Meta-Analytic Review. Journal of Youth and Adolescence. 48, 1637-1667, https://doi.org/10.1007/s10964$\underline{019-01072-5}$

Gunawan. (2011). Remaja dan Permasalahannya. Hanggar Kreator. Yogyakarta.

Hallsten, M. (2017). Is education a Risky Investment? The Scarring Effect of University Dropout in Sweden. European Sociological Review. 33(2):169-181. https://doi.org/10.1093/esr/jcw05 $\underline{3}$

Hedges, S. (2019). Children's work and parental investment in education in north- western Tanzania. $\mathrm{PhD}$ (research paper style) thesis,
Jurnal Ilmiah Ekonomi dan Bísnis

Vol. 18. No.1,Maret 2021 : 37-46

EISSN : $2442-9813$ ISSN : 1829 - 9822

London School of Hygiene \& Tropical

Medicine. https://doi.org/10.17037/PUBS.04 652445

Hermina, B., \& Didik, I. (2019). Peran Tokoh Masyarakat Dalam Menanggulangi Anak Putus Sekolah. Prosiding Seminar Nasional Pendidikan Dan Pembelajaran Bagi Guru Dan Dosen, 3: 50-57. https://conference.unikama.ac.id/ar tikel/index.php/fip/article/view/41 $\underline{5 / 335}$

Idrus, L. N. Al. (2019). Peranan Orang Tua Dalam Meningkatkan Motivasi Belajar Siswa SMPN 7 Sampit. Paedagogie, 5(1): pp. 41-46. ejournal.psikologi.fisipunmul.ac.id/ P-ISSN. 1907-1086, E-ISSN. 2656-4580.

Islam Sarker, M. N., Wu, M., \& Hossin, M. A. (2019). Economic effect of school dropout in Bangladesh. International Journal of Information and Education Technology. 9(2): 136-142, https://doi.org/10.18178/ijiet.2019. $\underline{9.2 .1188}$

Kim, Donggeun, \& Kim, Seoyong. (2018). Sustainable Education: Analyzing The Determinants of University Student Dropout by Nonlinear Panel Data Models. Sustainability (Switzerland), 10 (4), 1-18. https://doi.org/10.3390/su1004095 $\underline{4}$

Lestari Budi, Y. A. (2020). Penyebab Tingginya Angka Anak Putus Sekolah Jenjang Sekolah Dasar (SD). Jurnal Ilmiah Sekolah Dasar, $\quad 4(2), \quad$ https://doi.org/http://dx.doi.org/10. 23887/jisd.v4i2.24470.

Mayra, A., \& Mauricio, D. (2018). Factors to Predict Dropout at The Universities: A Case of Study in Ecuador. IEEE Global Engineering Education 
Jurnal Ilmiah Ekonomi dan Bísnis

Vol. 18. No.1,Maret $2021: 37-46$

EISSN : $2442-9813$

ISSN : 1829-9822

Conference, EDUCON, 1238-

1242.

https://doi.org/10.1109/EDUCO

N.2018.8363371 ISSN: 2165 9567

McDermott, E. R., Donlan, A. E., \& Zaff, J. F. (2019). Why Do Students Drop Out? Turning Points and Long-Term Experiences. Journal of Educational Research. 112(2), 270-282

https://doi.org/10.1080/00220671 .2018 .1517296

Mohan, A., Erickson, L., Gutjahr, G., Menon, R., Pillai, N. M., \& Nedungadi, P. (2018). Analysis of School Dropouts and Impact of Digital Literacy in Girls of The Muthuvan Tribes. Proceedings - 5th IEEE International Conference on MOOCs, Innovation and Technology in Education, MITE 2017, pp. 72-76 https://doi.org/10.1109/MITE.20 17.00019 P-ISBN: 978-1-53863190-4

Moh. Hafid Effendy, H. K. (2020). Tradisi Perjodohan di Kalangan Masyarakat Madura Pada Era Millenial. 1st International Conference on Morality (InCoMora). 1: pp. 248-256. Retrieved from http://incomora.unim.ac.id/index. php/InCoMora/article/view/68 Online ISSN: 2772-5720

Psacharopoulos, G., \& Patrinos, H. A. (2018). Returns to Investment in Education: A Further Update. Education Economics, 12(2): 111-134 https://doi.org/10.1080/09645290 42000239140 ISSN 0964-5292

Rabe, B. (2020). Schooling Inputs and Behavioral Responses by Families. In The Economics of Education, https://doi.org/10.1016/b978-0-
12-8153918.00016-1

Paperback/e-Book ISBN : 9780128153918-9780081026458

Syahdan, F. (2017). Hubungan Antara Keterampilan Kerja dengan Produktivitas Kerja. Jurnal Ilmiah Psikologi, 5 (1), pp. 1-10. ejournal.psikologi.fisipunmul.ac.id/ ISSN 2477-2674 (online), ISSN 2477-2666 (cetak)

T. Lestari, \& A. Setyadharma. (2019). Factors that Influence Drop Out of Vocational High School. Economics Development Analysis Journal, $\quad 8$ (3), 242-250 https://journal.unnes.ac.id/sju/inde x.php/edaj/article/view/30662 ISSN 2252-6560

Thuy Hang, B. T., Kaur, A., \& Busthami Nur, A. H. (2017). A selfDetermination Theory Based Motivational Model on Intentions to Drop Out of Vocational Schools in Vietnam. Malaysian Journal of Learning and Instruction. 14(1):, 1-21.

https://doi.org/10.32890/mjli2017. 14.1.1 ISSN-1675-8110

Trisnawati, W., Oktavia, D., Ikhsan, M. P., \& Megawati. (2020). Sosialisasi Peranan Orang Tua Terhadap Anak Di Desa Tirta Kencana. Jurnal Pengabdian Masyarakat, 1(1), 28-34. http://ejournal.stkipmmb.ac.id/index.php/JPM e-ISSN : 2722-0044 